International Journal of

Health, Medicine and

Nursing Practice

(IJHMNP)

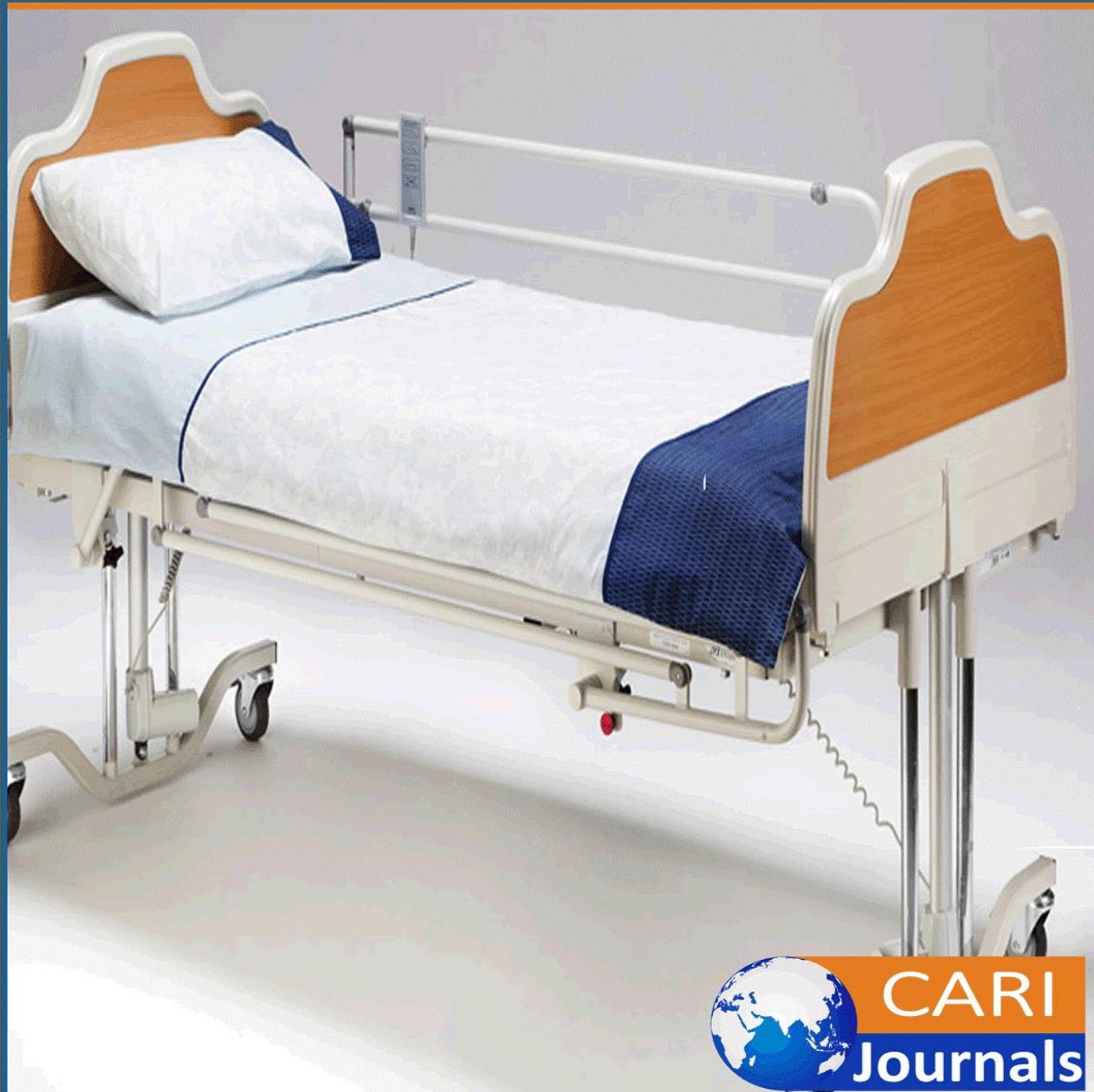




\title{
Assessment of Nurses Awareness Regarding Hemodialysis Complications: A Cross-Sectional Study in Lahore, Pakistan
}

\author{
$1 *$ Sadia Nasarullah \\ BSN (Post RN), Lahore School of Nursing, The University of Lahore \\ *Corresponding Author E-mail: sadiakhaan05@gmail.com \\ ${ }^{2}$ Muhammad Hussain
}

Associate professor Lahore School of Nursing, The University of Lahore, PhD Scholar, Master of Science in Nursing

${ }^{3}$ Kousar Perveen

Assistant Professor, Lahore School of Nursing, The University of Lahore, Master of Science in Nursing

${ }^{4}$ Muhammad Afzal

Principal, Lahore School of Nursing, The University of Lahore, Master of Science in Nursing

\begin{abstract}
Purpose: The purpose of the study was to assess the awareness of nurses regarding hemodialysis complication in Lahore, Pakistan.

Methodology: Descriptive research design was used to conduct this study. The study was conducted at the Hemodialysis Unit at tertiary Care Hospital Lahore, Pakistan. The sample of the study consisted of 110 nurses (female) working in the hemodialysis unit, aged between 18 and 55 years has agreed to participate in this study. The self-administered questionnaire sheet was used to collect study-related data with the following sections. Part 1: "Nurse's socio-demographic characteristics", Part 2: "Nurses 'Awareness of Hemodialysis Practices", Part 3: "Nurses' Awareness of Hemodialysis Complications"

Findings: Most of the nurses had a good level of knowledge about the complications of hemodialysis and very few of them had little knowledge. Most of the nurses were females and were aged 18-27.

Unique contribution to theory, practice and policy: Further research should be done on a larger sample of them which focuses on their practice and should make the results of their study regarding their knowledge and its reflection on their practice
\end{abstract}

Keywords: Awareness, Hemodialysis, Complications, Nurses, Assessment 
International Journal of Health, Medicine and Nursing Practice

ISSN 2710-1150 (Online)

Vol. 3, Issue No. 3, pp 13- 24, 2021

$\underline{\text { www.carijournals.org }}$

\section{INTRODUCTION}

Chronic kidney disease is a major health problem that continues to grow in the world and in our country. The World Health Organization's report, published in 2018, states that 1.2 million people died of kidney disease in 2015, and estimates that 2.3-7.1 million people became chronic by the end of kidney disease in 2010. He died without access to dialysis, and he has died. It has increased by $32 \%$ since 2005 . The same report states that 2.1 million people received dialysis treatment in 2010 and by 2030, the number of people receiving dialysis treatment will double (Luyckx, Tonelli, \& Stanifer, 2018). The burden of chronic kidney disease is a serious condition that is increasing in proportion to the world. Chronic renal failure is considered a permanent impairment of kidney function. It is considered a deadly and life-threatening disease, in which only hemodialysis or peritoneal dialysis can survive. End-stage kidney disease is a lifelong disease that requires continuity of care, including hemodialysis, which progresses through the dire consequences of arteriovenous fistula (Vasuki \& Kim, 2020).

Nurses are professionals who usually care for patients with serious injuries or serious illnesses. In addition, they are the closest provider of healthcare services to professional patients, and when patients are seriously ill, they have no choice but to rely on nurses. Therefore, trust as an invaluable asset of nursing plays an important role in patient-nurse relationships and can have a positive impact on health outcomes (Ahmadpour, Ghafourifard, \& Ghahramanian, 2020). Nurses should assess patients' cultural individual needs, which change with each stage of life's restructuring, and provide the right care at the right time to enhance positive experiences (Kim \& Yang, 2021). Central Venus Catheters are an essential component of hemodialysis care. They are present in about $43 \%$ to $73 \%$ of patients with hemodialysis. However, complications associated with the use of Central Venus Catheters not only affect patients' illness and mortality, but also increase the cost of medical treatment and other disadvantages in the length of hospital stay (Vasuki \& Kim, 2020).

Home dialysis methods are used in a minority of patients with kidney failure in the United States. During the 2018 National Kidney Foundation - Kidney Disease Outcomes Quality Initiative Home Dialysis Conference, a number of ideas were suggested to address barriers to maintaining and maintaining home dialysis therapies. Minimize (Chan et al., 2020). One clinical setting in which patients need to rely on the nurses caring for them is the hemodialysis ward. Responsibility for the care of patients with kidney disease and diarrhea Nurses need to build trust to provide high quality care. Considering the fact that the role of nurses in the dialysis unit is to perform dialysis therapy and to be in constant contact with patients who typically undergo dialysis three to four hours a week, to provide high quality dialysis nurses. I have an important and undeniable role in quality care for these patients (Shahgholian, Ghafourifard, \& Shafiei, 2011). In addition, they teach about treatment and dietary behaviors, controlling fluid intake in these patients, and overcoming the complications of dialysis. Therefore, it is important to establish an effective trust relationship between patients and nurses in the dialysis unit. Although trust is a powerful asset in the relationship between patients and nurses, it can have positive results for patients (Ahmadpour et al., 2020). 


\section{Significance of the study}

Despite proper dialysis, many dialysis patients still show uncontrollable high blood pressure, which is a major risk factor for heart disease. Other recurrent complications during dialysis include post-dialysis fatigue syndrome, nausea and vomiting, headache, pain, itching, and pyrogenic reactions (Song, 2018). Therefore, for these reasons, there is a clear need for further review of nurses' knowledge and practices regarding the complications of hemodialysis. In addition, nurses have the largest number of personnel working in hemodialysis units. Any impairment in their performance will affect the patient and the patient's quality of life at the level of care. For these reasons, the study will be conducted to implement standardized nursing care for hemodialysis patients.

\section{Statement of the Problem}

The role of the nurse is crucial in the prevention and early detection of complications of hemodialysis, and the great efforts made by researchers conducting medical experiments in tertiary care hospitals. It was observed that the nurses working in the hemodialysis unit lacked information about the complications of hemodialysis, so this study targeted these nurses to assess their awareness of the complications of dialysis.

Show the research gap here as the last paragraph to justify the need for this research

\section{Objectives of Study}

The objective of the study to assess the awareness level of nurses working in hemodialysis unit at Lahore General Hospital Lahore, Pakistan.

\section{Research hypothesis}

\section{Null hypothesis}

They have no awareness regarding hemodialysis complications.

\section{Alternative hypothesis}

They have awareness regarding hemodialysis complications. 


\section{LITERATURE REVIEW}

\section{Theoretical Review}

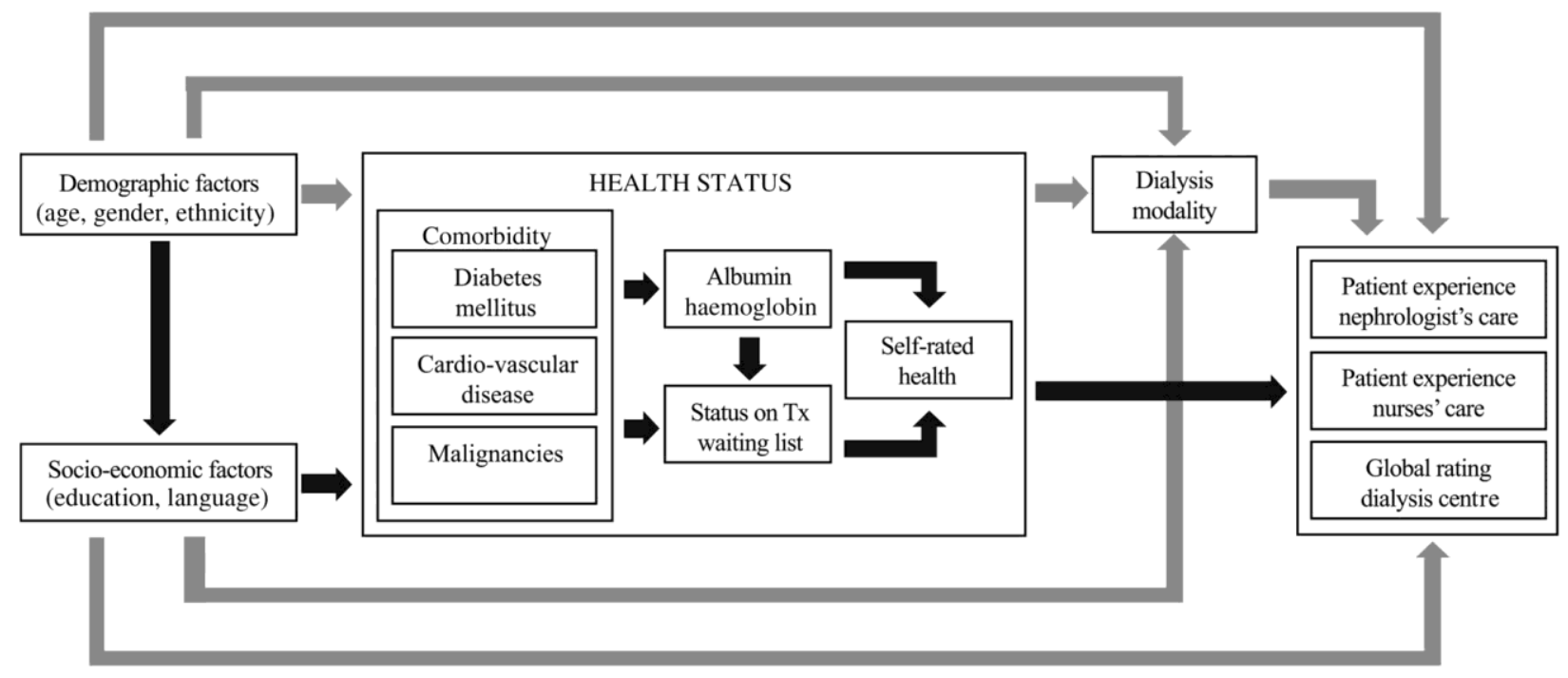

The theoretical framework describes the hypothetical relationship between patient characteristics, and health status, and patient experience and care rating. Black arrows indicate a path of interest for this particular study. Demographic and social and economic factors are also associated with patient satisfaction as well as health. With reference to the latter, demographic factors were considered a justification for the relationship between social and economic factors and health. As a result, self-esteem and physical health proved to be the determinants of patient satisfaction, with population and, to a lesser extent, social and economic factors at stake. Previous studies have shown that socio-demographic and health status factors influence the choice of dialysis status. Finally, modality appears to affect patient ratings (van der Veer et al., 2012).

\section{Empirical Review}

Hemodialysis can improve the patient survival rate, but it also negatively affects all aspects of patients' life (Shahnavazi et al., 2018). Hemodialysis is the most common treatment for end-stage kidney disease worldwide. This therapy can extend the life of countless patients, but at the same time, it can lead to many mental, social, economic and physical complications, which can have a negative impact on their quality of life. Improving the nutritional status of hemodialysis patients is an essential component to minimizing the complications of the disease (Zidan et al.). A recent study of the incidence and prevalence of hemodialysis patients in Egypt associated with failure of modern access is 5.5\%. Longer waits are needed to produce and perform hemodialysis. All of these results are due to failure of vascular access (Salem, Eldein, Aly, \& Dawood).

End-stage renal disease is known as irreversible renal dysfunction, which is severe enough to be fatal in the absence of transplantation or hemodialysis. The End-stage renal disease is included under the National Kidney Foundation Kidney Disease Outcome Criteria Kidney Disease Rating Phase 5, where it is less than 15 milliliters per millimeter per millimeter in the body surface area. Indicates individuals with estimated glomerular filtration rates, leading to impaired renal function 
International Journal of Health, Medicine and Nursing Practice ISSN 2710-1150 (Online)

that is now sufficient to sustain life without the use of alternative kidney therapy in the form of transplantation or dialysis do not have (Zidan et al.).

Hemodialysis is the process of pumping toxins and excess fluid from the blood into the baby's blood through a hemodialysis machine and then injecting the baby back into the blood. Needles are inserted into the arteriovenous fistula or a graph to remove and reuse blood, usually in the arm. Hemodialysis is an intermittent exercise that is done 2-4 times a week, with a duration of 3-4 hours in each session, depending on a number of factors providing an effective dialysis (Machaly, Bahgat, Hassan, \& Kafl). Dialysis is one of the most common kidney transplant therapies. However, the hemodialysis unit is a high source area for contamination from blood and body fluids. However, infection risk transmission can be reduced through infection control exercises (Abouelfadle, Abdel Aziz, \& Ahmed, 2021).

Complications related to vascular access to hemodialysis have a major impact on disease and mortality. In addition, hemodialysis patients are hospitalized once or twice a year due to complications of modern access space. According to a recent study for hemodialysis patients who receive 14 to $17 \%$ hospitalization annually (Kaushal \& Wilson, 2017). The most common complication of vascular access as a result of contamination during access creation and repeated use is infection. Other common complications of vascular perforation include sudden bleeding. It compromises the basic mechanisms of hemostasis, including thrombocytopenia and platelet deficiency. Sudden bleeding causes chronic anemia, which is common in uremic patients, and also has a negative effect on the rheological components of platelet muscle wall interactions. Another common complication of arteriovenous is thermo bass which can lead to multiple dialysis sessions, increased patient admission, and temporary hemodialysis catheter replacement (Quencer \& Oklu, 2017).

Nursing diagnosis focuses on identifying the signs and symptoms of renal failure and related complications, and assessing the psychological effects of renal failure on the child and family (Brown et al., 2019). The dialysis nurse plays an important role in providing information, care, support, understanding and treatment to pediatric patients and their families throughout the illness. Nursing management should be provided to reduce the stress of dealing with kidney disease complications and lifelong dialysis (Arnold-Chamney, Podham, \& Anderson, 2019). Nurses play an important role in hemodialysis. He contributed to the prevention, promotion and treatment of the dialysis unit while maintaining the gynecological environment while manufacturing all the necessary equipment in Countercurrent chromatography injection kits and septic techniques. They were responsible for applying their knowledge to reduce the incidence of infection. The reason for not paying attention to the recommended guidelines of evidence based practice to stop Catheterrelated bloodstream infection is the lack of knowledge of guidelines with other members of the nurses' health team where they can enroll or take care of central venous catheter. Providing the best practices for your care during (Abdo, Ramadan, Tosson, \& Al-Fadhli, 2020; Aiken et al., 2012). 
International Journal of Health, Medicine and Nursing Practice

ISSN 2710-1150 (Online)

Vol. 3, Issue No. 3, pp 13- 24, 2021

WwW.carijournals.org

\section{METHODOLOGY}

Study design: A cross sectional study was conducted.

Study setting: The present study was conducted at the dialysis unit of tertiary care hospital in Lahore, Pakistan.

Duration of the study: The study was accomplished from February 2021 to May 2021

Target population

Sample size

Sample size is 110 .

Sampling technique: Convenience sampling method was used to collect data.

\section{Inclusion criteria}

The nurses who have been working in dialysis unit of tertiary care hospital in Lahore, Pakistan and have one year of experience was included in the study.

\section{Exclusion criteria}

The nurses who have been working other than dialysis unit of tertiary care hospital in Lahore, Pakistan was excluded from the study.

\section{Data collection procedure}

The data was collected by questionnaire guide that was derived from Ali, et al. A questionnaire with different dimensions was used to assess awareness of dialysis nurses regarding dialysis complications. Informed consent obtained from participated nurses, after explaining the nature and purpose of the study.

\section{Data analysis procedure}

Data analysis using SPSS version 25 (Data Package for Social Science). Data was presented as; (Number Percentage (\%) - Average and Standard Deviation (SD) -Chi-Square Test was used to correlate the dependent and independent variables and find $\mathrm{P}$-value. 


\section{FINDINGS AND PRESENTATION}

\section{Socio-demographic characteristics}

120 nurses contributed in the studies and 110 completed and return the survey questioner, with return rate of $95.7 \%$. All 110(100\%) were female nurses, 49(44.5\%) single and 61(55.5\%) married, $88(80.0 \%)$ had diploma in general nursing, 20(18.2\%) had bachelor's degree and 2(1.8\%) had master degree. $51(46.4 \%)$ of work experience equals or less than 1 year, 27(24.5\%) had 1-5 years, $25(22.7 \%)$ had 5-10years and 7(6.4\%) had 10-20 years' experience.

Table 1: socio-demographic characteristics

\begin{tabular}{|c|c|c|}
\hline Variables & Frequency $(f)$ & Percentage $(\%)$ \\
\hline \multicolumn{3}{|l|}{ Age } \\
\hline $18-<28$ years & 73 & 66.4 \\
\hline $28-<38$ years & 37 & 33.6 \\
\hline \multicolumn{3}{|l|}{ Gender } \\
\hline Female & 110 & 100.0 \\
\hline \multicolumn{3}{|l|}{ Marital status } \\
\hline Single & 49 & 44.5 \\
\hline Married & 61 & 55.5 \\
\hline \multicolumn{3}{|l|}{ Level of education } \\
\hline Diploma in Nursing & 88 & 80.0 \\
\hline Bachelor of Science in Nursing & 20 & 18.2 \\
\hline Master & 2 & 1.8 \\
\hline \multicolumn{3}{|l|}{ Years of experience } \\
\hline Less than 1year & 51 & 46.4 \\
\hline $1-5$ years & 27 & 24.5 \\
\hline $5-10$ years & 25 & 22.7 \\
\hline $10-20$ years & 7 & 6.4 \\
\hline
\end{tabular}

\section{Nurse's awareness regarding hemodialysis practice}

Table 2 showed that the most of nurses had good knowledge in most of the items related to dialysis procedure. 
Table 2: Percentage distribution for nurse's awareness regarding hemodialysis practice

\begin{tabular}{|c|c|c|c|c|c|}
\hline \multirow[t]{2}{*}{ S/no } & \multirow[t]{2}{*}{ Variable } & \multicolumn{2}{|c|}{ Know } & \multicolumn{2}{|c|}{ Uncertain } \\
\hline & & $f$ & $\%$ & & $\%$ \\
\hline 1 & $\begin{array}{l}\text { washing hands importance between patients and } \\
\text { another }\end{array}$ & 108 & 98.2 & 2 & 1.8 \\
\hline 2 & putting gloves before dealing with the patient & 107 & 97.3 & 3 & 2.7 \\
\hline 3 & Using sterile technique during insertion of the catheter & 109 & 99.1 & 1 & 0.9 \\
\hline 4 & Assessing vascular access for infection signs & 108 & 98.2 & 2 & 1.8 \\
\hline 5 & Evaluating the vascular access site for functioning & 110 & 100.0 & & \\
\hline 6 & Importance of checking blood pressure through dialysis & 108 & 98.2 & 2 & 1.8 \\
\hline 7 & Necessity of checking vital signs every half to full hour & 110 & 100.0 & & \\
\hline 8 & Catheter insertion accurately (placement). & 110 & 100.0 & & \\
\hline 9 & The component of dialysate solution. & 109 & 99.1 & 1 & 0.9 \\
\hline 10 & $\begin{array}{l}\text { Set the speed of the blood stream through the (circuit set } \\
\text { of dialysis). }\end{array}$ & 110 & 100.0 & & \\
\hline 11 & $\begin{array}{l}\text { Monitor the weight of patient before and after the } \\
\text { dialysis }\end{array}$ & 109 & 99.1 & 1 & 0.9 \\
\hline 12 & Types of vascular access site & 110 & 100.0 & & \\
\hline 13 & Dealing with all alarms in the machine & 108 & 98.2 & 2 & 0.9 \\
\hline 14 & $\begin{array}{l}\text { Importance of (PPE) used in the unit especially for } \\
\text { hepatitis patient }\end{array}$ & 110 & 100.0 & & \\
\hline 15 & $\begin{array}{l}\text { Necessarily document machine setting and each nursing } \\
\text { procedure during and after hemodialysis }\end{array}$ & 108 & 98.2 & & \\
\hline
\end{tabular}


International Journal of Health, Medicine and Nursing Practice ISSN 2710-1150 (Online)

Vol. 3, Issue No. 3, pp 13- 24, 2021

WwW.carijournals.org

\section{Relation between nurse's awareness with level of education}

There is a significance relationship between nurse's awareness regarding hemodialysis complications with level of education (table 3).

Table 3: Relation between nurse's awareness regarding hemodialysis complications with level of education

\begin{tabular}{lccccc}
\hline Variable & & \multicolumn{2}{c}{ Complication } & Total & P. value \\
\cline { 3 - 4 } & & $\begin{array}{c}\text { Poor } \\
\text { Awareness }\end{array}$ & $\begin{array}{c}\text { Good } \\
\text { Awareness }\end{array}$ & & \\
\hline $\begin{array}{l}\text { Level of } \\
\text { education of }\end{array}$ & diploma & 27 & 61 & 88 & 0.042 \\
participants & BSN & 1 & 19 & 20 & \\
& MSN & 0 & 2 & 2 & \\
Total & & 28 & 82 & 110 & \\
\hline
\end{tabular}

\section{DISCUSSION, CONCLUSION AND RECOMMENDATIONS}

\section{Discussion of the findings}

The study found that $66.4 \%$ of nurses were aged 20 to 30 . The results of this study were similar to those of (Bakey, 2014) who stated that most of the study participants were between the ages of 20 and 30. The results were similar to those of (Ali, Mahammad, El-mohsen, \& Ali, 2018) who reported that approximately $62.9 \%$ of the respondents in the study were in the age group of 20 to 30 years.

The results also showed that most of the nurses were married, and this was agreed with (Ali et al., 2018) in which $>1 / 2$ of the study sample were married. This is similar to the results of (Bakey, 2014) study, where most of the study participants were married.

About the 'years' of experiences. It has been observed that more than one third of nurses have one to five years of experience. The results of the present study agree with Jaffar (2012) who reported that more than half $(63.3 \%)$ of nurses' experience varied from 1 to 5 years. This is similar to Becky (2014), where most study participants have 1 to 5 years of experience. The study did not agree with Ahmed, (2011) who said that most of the nurses have 5 to 10 years of experience. Another study (Abdel-Latif, ELghany, AbdEl-Aziz, \& Abd ELhamid, 2019), shows that most participants had $5<10$ years of experience.

The results of the study revealed that all participants were females. The study agreed with the study, which was conducted in the state of Khartoum in which most of the nurses were female. This was similar to (Ali et al., 2018), the participants were female, while this study was denied with Jaffar (2012) which was conducted in teaching hospitals in Baghdad, and it was also reported 
that $1 / 2$ of the samples were males. Another study conducted by (Bakey, 2014) found that most of the study participants were males.

This study represents that most of the study participants were $80.0 \%$ diploma holders. The study is similar to a study by (Abdel-Latif et al., 2019), who said that most nurses have diploma holders. There was disagreement with him (Thomas et al., 2016) who got high representation of bachelor.

Regarding the complications of hemodialysis, the results of the present study show that all nurses have adequate knowledge about the procedure of hemodialysis. In addition, the majority of the samples had adequate awareness of six items but a small number of nurses had moderate awareness of one item.

Most of the nurses had an appropriate level of awareness about the nurses' awareness of the hemodialysis procedure. It can be explained that; Most of the nurse's experience years were not less than ten years. He agreed with (Abd-Alfatah, Ahmad, \& Mohamed, 2013) who said that nurses in education are better at their overall level of awareness. These results were similar to those of (Ali et al., 2018) stated that nurses had adequate awareness level regarding hemodialysis complications.

Regarding the relationship between the level of hemodialysis complications and the level of education of the nurse's awareness, the present study found that a statistically significant relationship was similar to that of (Abd-Alfatah et al., 2013), who reported that the nurse's was a statistically significant relationship between awareness and education level of hemodialysis complications.

\section{Conclusion}

It was concluded that the nurses working in the dialysis unit of the tertiary care hospital in Lahore, Pakistan had adequate knowledge about the complications of hemodialysis. There is a significant statistical relationship between hemodialysis complications and the nurse's awareness of educational level.

\section{Recommendations}

As a result of the present study, it is recommended that availability of manual procedures for nurses who are aware of any problem that may arise in the unit. In order to maintain and improve the level of awareness and practice, training programs should be frequently supported in order to permanently fix and recreate the knowledge and skills of the nurses.

\section{Finding Source}

No any funding source.

\section{Acknowledgment}

I wish to convey my appreciation to all who contributed extremely to the source of this study. Mr. Muhammad Hussain and Ms. Kousar who are my lecturer in research methodology and supervisor during the whole program, from February 2021 to May 2021 for their continued encouragement. 
International Journal of Health, Medicine and Nursing Practice ISSN 2710-1150 (Online)

Vol. 3, Issue No. 3, pp 13- 24, 2021

www.carijournals.org

\section{Conflict of interest}

The author declared no any conflict of interest

\section{References}

Abd-Alfatah, A., Ahmad, A., \& Mohamed, F. (2013). Assessment of Nurses' Knowledge and Practice Related to Nursing Care of Children Undergoing Hemodialysis at Assiut City. Unpublished Master Thesis, Department of Medical Surgical Nursing Science. Faculty of Nursing, Asuit University.

Abdel-Latif, N. A., ELghany, O. A., AbdEl-Aziz, M. A., \& Abd ELhamid, S. K. (2019). Assessment of Nurses Knowledge and Practices Regarding Complications of Hemodialysis Patients in Intensive Care Unit. Assiut Scientific Nursing Journal, 7(19), 165-174.

Abdo, N. M., Ramadan, M. A., Tosson, M. M., \& Al-Fadhli, M. A. (2020). Effectiveness of An Educational Program on Knowledge and Practices Regarding Care of Central Venous Catheters among Dialysis Nurses. Egyptian Journal of Community Medicine, 38(1).

Abouelfadle, S., Abdel Aziz, T., \& Ahmed, D. A. A. S. (2021). Assessment of Safe Handling and Disposal of Laundry in Hemodialysis Unit. Journal of Bioscience and Applied Research, $1-16$.

Ahmadpour, B., Ghafourifard, M., \& Ghahramanian, A. (2020). Trust towards nurses who care for haemodialysis patients: a cross-sectional study. Scandinavian journal of caring sciences, 34(4), 1010-1016.

Aiken, L. H., Cimiotti, J. P., Sloane, D. M., Smith, H. L., Flynn, L., \& Neff, D. F. (2012). Effects of nurse staffing and nurse education on patient deaths in hospitals with different nurse work environments. The Journal of nursing administration, 42(10 Suppl), S10.

Ali, S. A., Mahammad, Z. A. E.-1., El-mohsen, A., \& Ali, S. (2018). Awareness of Nurses Regarding Hemodialysis Complications. Assiut Scientific Nursing Journal, 6(15), 126-132.

Arnold-Chamney, M., Podham, M., \& Anderson, J. (2019). Chronic kidney disease Chronic care nursing: A framework for practice (pp. 275-294): Cambridge University Press.

Bakey, S. J. (2014). Evaluation of Nurses' Practices throughout Hemodialysis Treatment for Patients in hemodialysis unit at Baghdad teaching hospitals. Kufa Journal for Nursing Sciences, 2(2), 1-16.

Brown, K. M., Jones, M. B., Moore, L., Meliones, C., Montgomery, J. A., \& Ascenzi, J. (2019). Advanced Nursing Practice in Pediatric Cardiac Critical Care Critical Heart Disease in Infants and Children (pp. 82-93. e82): Elsevier.

Chan, C. T., Collins, K., Ditschman, E. P., Koester-Wiedemann, L., Saffer, T. L., Wallace, E., \& Rocco, M. V. (2020). Overcoming barriers for uptake and continued use of home dialysis: an NKF-KDOQI conference report. American Journal of Kidney Diseases, 75(6), 926-934. 
International Journal of Health, Medicine and Nursing Practice ISSN 2710-1150 (Online)

Vol. 3, Issue No. 3, pp 13- 24, 2021

$\underline{\text { www.carijournals.org }}$

Kaushal, K., \& Wilson, S. E. (2017). Thrombophilia as a cause of recurrent vascular access thrombosis in hemodialysis patients Vascular Surgery (pp. 115-118): CRC Press.

Kim, S., \& Yang, J. (2021). An Alternative View of a Hemodialysis-Life Balance: Life Reorganization of Korean Patients Undergoing Hemodialysis. Journal of Transcultural Nursing, 1043659620988339.

Luyckx, V. A., Tonelli, M., \& Stanifer, J. W. (2018). The global burden of kidney disease and the sustainable development goals. Bulletin of the World Health Organization, 96(6), 414.

Machaly, E. R., Bahgat, R. S., Hassan, H. H., \& Kafl, R. H. Effect of Implementing Evidence Based Nursing Guidelines on Nurses' Performance about Care Provided for Children Undergoing Hemodialysis.

Quencer, K. B., \& Oklu, R. (2017). Hemodialysis access thrombosis. Cardiovascular diagnosis and therapy, 7(Suppl 3), S299.

Salem, M. F. A., Eldein, S. M. A., Aly, A. P. R. A. Y., \& Dawood, R. F. A. Factors Associated with Hemodialysis Patients' Vascular Accesses Failure as Perceived by Nurses and Patients: a retrospective study.

Shahgholian, N., Ghafourifard, M., \& Shafiei, F. (2011). The effect of sodium and ultra filtration profile combination and cold dialysate on hypotension during hemodialysis and its symptoms. Iranian journal of nursing and midwifery research, 16(3), 212.

Shahnavazi, M., Parsa-Yekta, Z., Yekaninejad, M.-S., Amaniyan, S., Griffiths, P., \& Vaismoradi, M. (2018). The effect of the emotional intelligence education programme on quality of life in haemodialysis patients. Applied Nursing Research, 39, 18-25.

Song, J. H. (2018). Complications of hemodialysis The essentials of clinical dialysis (pp. 105126): Springer.

Thomas, A., Silver, S. A., Rathe, A., Robinson, P., Wald, R., Bell, C. M., \& Harel, Z. (2016). Feasibility of a hemodialysis safety checklist for nurses and patients: a quality improvement study. Clinical kidney journal, 9(3), 335-342.

van der Veer, S. N., Arah, O. A., Visserman, E., Bart, H. A., de Keizer, N. F., Abu-Hanna, A., . . . Jager, K. J. (2012). Exploring the relationships between patient characteristics and their dialysis care experience. Nephrology Dialysis Transplantation, 27(11), 4188-4196.

Vasuki, R., \& Kim, J. (2020). Nursing Care of Arteo Venous Fistula for the Patient Undergoing Hemodialysis. International Journal of Internet, Broadcasting and Communication, 12(4), 188-195.

Zidan, S., Badrasawi, M., Nimer, B., Sabha, K. A., Taninieh, R., \& Rasheed, S. Knowledge of haemodialysis patients about Nutrition: a cross-sectional study from Palestine. 